\title{
Price distortions and municipal bonds premiums: evidence from Switzerland
}

\author{
Darko B. Vukovic ${ }^{*}$ (D, Carlos J. Rincon and Moinak Maiti
}

${ }^{*}$ Correspondence:

vdarko@hotmail.rs Department for Finance,

St. Petersburg

School of Economics

and Management, National

Research University Higher

School of Economics,

Kantemirovskaya

3A, Office 331, Sankt

Petersburg 194100, Russia

\begin{abstract}
This study examines the pricing of municipal bonds before and after a currency shock in Switzerland. Two approaches are used to decompose the municipal to treasuries bond spreads into liquidity, maturity, and default risk premiums. The first approach is the model of the cross-sectional instrumental variables, and the second approach is the model of the instrumental variables with panel data. This study examines the composition of spreads for both approaches, in three scenarios: before, throughout, and after the currency shock. The study performed Durbin-Wu-Hausman tests for each decisive model to verify endogeneity issues, including the Lagrangian Multiplier test, the Cragg-Donald Wald F statistic to confirm the relationship of instrumental and endogenous variables, and the structural break test (Bai-Perron test) to determine the existence of structural breaks in bond distortions. This study finds that the currency price distortions of the Swiss franc in January 2015 made long-run changes in the composition of the municipal bond spreads. This research contributes to the understanding of municipal bond pricing by showing that default risk accounts for a large portion of the municipal bond spread, while maturity risk plays a lesser role. According to our empirical findings, unexpected large currency price shocks may have long-term implications on the municipal bond spreads.
\end{abstract}

Keywords: Municipal bonds, Risk premiums, Bond spreads, Price distortions

JEL Classification: E4, E43, E47, G17

\section{Introduction}

Over the last decade, scholars have become increasingly interested in the field of price distortions and municipal bonds premiums. Except for taxation reasons (fiscal policies and distortions), which are mostly analyzed in the studies of Ang et al. (2010), Babina et al. (2015), and Landoni (2018), the focus of the studies are also on default premium (Wang at el. 2008; Schwert 2017; Vukovic et al. 2020a, b, 2021a, b) and liquidity premium (Longstaff 2011; Jiang 2019; Li and Schürhoff 2019). Price distortions, by definition, describe significant gaps between mark-to-market prices and a plausible range of economic values of certain assets. Like information inefficiency, price distortions draw mispricing of financial assets relative to their fundamental value. This phenomenon is especially pronounced in conditions caused by shocks (crisis events), affecting banks (Kou et al. 2021b), companies (Kou et al. 2021a; Maiti et al. 2020), markets (Grubisic author(s) and the source, provide a link to the Creative Commons licence, and indicate if changes were made. The images or other third party material in this article are included in the article's Creative Commons licence, unless indicated otherwise in a credit line to the material. If material is not included in the article's Creative Commons licence and your intended use is not permitted by statutory regulation or exceeds the permitted use, you will need to obtain permission directly from the copyright holder. To view a copy of this licence, visit http:// creativecommons.org/licenses/by/4.0/. 


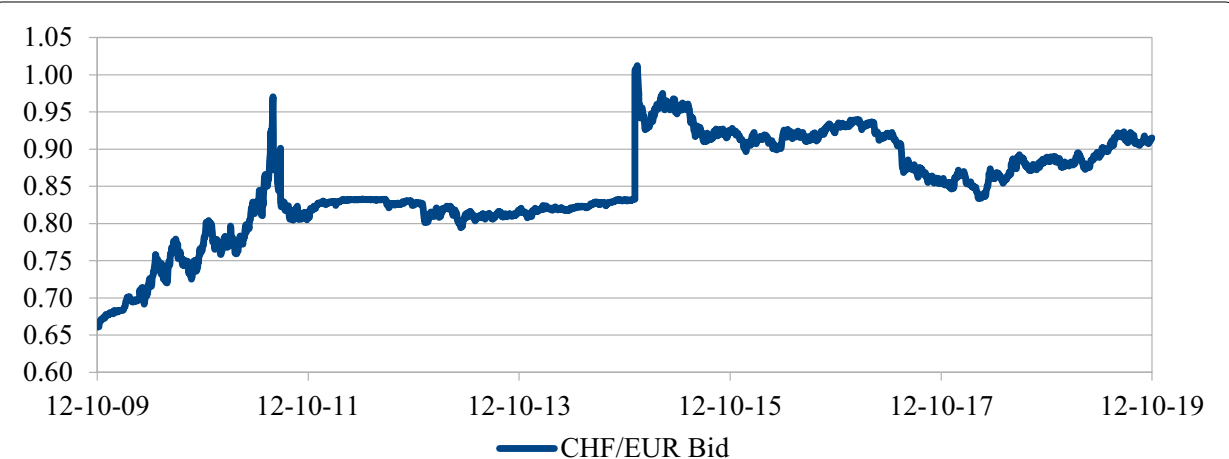

Fig. 1 Swiss Franc/Euro FX Cross Rate. This figure presents the Swiss franc to euro currency exchange price time series. In it, two price shocks can be identified, one in early August 2011 and another one on January 15th, 2015. It is clear to say that the second one was a rather sharper price shock. Source: EIKON Reuters

et al. 2011; Wen et al. 2019) and almost all other stakeholders whose agents (or groups of agents, in Zha et al. 2020) have decision-making challenges.

Herewith fiscal policy and risks arising from sudden events, price distortions, and municipal bonds premiums are also affected by the monetary policy and exchange rate changes. On January 15th, 2015 the Swiss National Bank (SNB) suddenly announced that it would no longer hold the Swiss franc (CHF) at a fixed exchange rate with the euro (EUR) (Swiss National Bank 2015). As a result, the Swiss franc soared, from a 0.8325 CHF per one EUR as of closing on Tuesday, January 14th, to 1.0014 CHF/EUR (source EIKON Refinitiv platform, Fig. 1) on Thursday, January 16th, for an immediate appreciation of $20 \%$ in one day. While the Swiss stock market collapsed, many mutual and hedge funds around the world realized large losses, and the 10-year Swiss treasury yield dropped some 251 bps in the same couple of days.

The SNB started to peg its currency to the euro in 2011, in the middle of the European sovereign crisis. The Swiss franc is a safe asset for global investors, who buy it when there is a global risk. Likewise, investors believe that the Swiss government is one of the safest for investments, globally, and their money is safe in their hands. This preference led to the raised price of the Swiss franc when the aforementioned crisis caused financial damages in Europe. A higher franc value hurts Switzerland though, as their economy is heavily dependent on selling their production abroad, that is, exports of goods and services are worth around 70\% of GDP (Swiss National Bank 2015). As a way to bring down the franc's value, the SNB created new francs and bought euros with them, in a very active intervention in this market for the next few years. The increase in the supply of francs in the foreign exchange markets caused the franc's price to fall as low as 0.7946 against the euro, in May of 2013 and never fluctuating above 0.833, which reflects a price reached in June of 2012 (Swiss National Bank 2015). By 2014, the SNB, with this policy, had accumulated more than 500 billion dollars in foreign currency (Lleo and Ziemba 2015), equivalent to about $70 \%$ of Swiss GDP. Finally, the SNB suddenly ceased to intervene in the foreign exchange market on January 15th, 2015, for a few reasons. First, the Swiss feared that the printing of so many francs would eventually lead to hyperinflation. Second, there were expectations that the European Central Bank would introduce a quantitative easing package that would result in the creation of money to buy the 


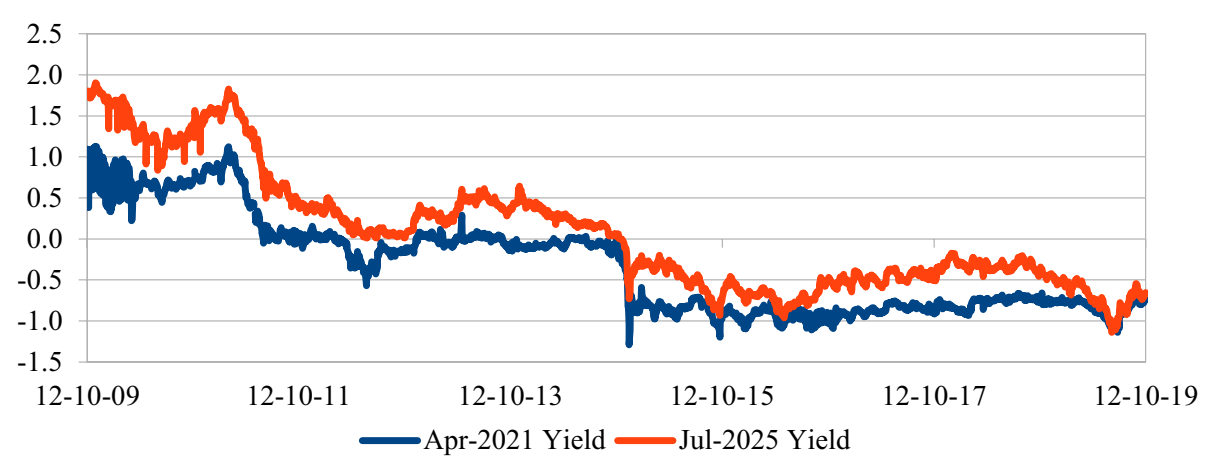

Fig. 2 CHGV Apr-2021 and Jul-2025. This figure presents the 10-year Swiss government bond yields time series. While the trend in the 2021 maturity treasuries shows decreasing yields from 2021 until early 2015, the opposite happens on the 2025 maturity treasury yield trend for the period after the currency price shock.

Source: EIKON Reuters

government debt securities of euro-zone countries, and thus may push down the price of the euro, requiring the SNB to print even more francs to maintain a ceiling of its price. Third, during 2014, the euro depreciated against other major currencies, meaning that the franc, while pegged to the euro, had depreciated against those currencies too. As the US economy recovered from the great recession, the franc depreciated around 13\% against the dollar, deteriorating the Swiss exports to the US and other countries. Therefore, if the Swiss franc was not so competitive anymore, then the SNB had no reason to continue keeping it weak (The Economist 2015). Freeing up a low enough Swiss franc, and having no-threat of a possible re-intervention, made foreign investors heavily purchase the Swiss treasury securities with them.

Figure 2 shows that although the Swiss treasury yields were in an already downward trend since 2011, the trend strengthened with the dis-intervention in the franc rates. For instance, the (at the time) 10-year Swiss treasury bonds were trading at $1.123 \%$ yield in the spring of 2011, dropping to a low of -0.571 on January 14th, 2015, right before the event, for a drop of more than 550 bps in 4 years; while the 10-year Swiss treasury bonds were trading at $-0.182 \%$ yield, at the time, on January 14 th, 2015 , dropping to a low of -0.733 on Friday, January 23rd, 2015, for a drop of the same $550 \mathrm{bps}$, in a matter of just a week and a half.

The Swiss treasury yields, and their municipal bond yields dropped dramatically after the currency shock. As with the safety of their treasuries, the Swiss municipalities' debt securities offer investors a safe haven when risks appear. Should a Swiss municipality fail to meet its financial obligations, the Swiss government would back them as a last resort guarantor. Most Swiss municipal bonds had the same downward trend since 2011 as the treasuries, and one expected that the trend would strengthen with the dis-intervention in the franc rates (Eikon Refinitiv platform 2020). The rational investor would have expected the yield spread to the treasury's benchmark of these municipalities to remain the same or even to narrow.

In Fig. 3, it can be seen that the benchmark spread of the 10-year Zurich municipal bonds, at the time, accounted for an average of about 40 bps during 2011-2012, narrowing below 20 bps on January 14th, 2015, right before the event. Meanwhile, the 10-year Zurich municipal bonds at the time were trading at a benchmark spread of $21 \mathrm{bps}$ on 


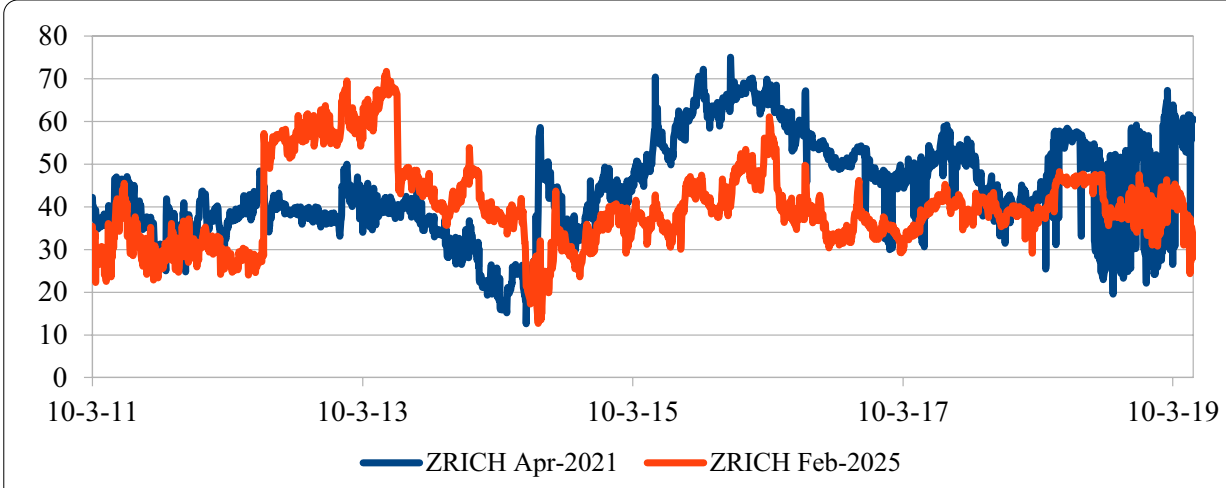

Fig. 3 ZURICH Apr-2021 and Feb-2025 Benchmark Spreads. This figure displays the 10-year Zurich municipal bond yield spreads series. While the trend in the 2021 maturity municipals shows decreasing spreads from 2011 until early 2015, the opposite happens on both the 2021 and 2025 spreads for the period after the currency price shock. Source: EIKON Reuters

January 14th, 2015. This led to the widening of up to about 60 bps by the end of 2015, a spread even wider than that in 2011 (EIKON Refinitiv platform, Fig. 3).

Price distortions describe significant gaps between mark-to-market prices and a plausible range of economic values of certain assets. Like information inefficiency, price distortions draw the mispricing of financial assets relative to their fundamental value. In the context of this study, we identify that the SNB's constant intervention in the Swiss franc rates for the 2011-2015 period led to its currency value, to the euro, being priced at levels significantly different from its fundamental values. Proof of this identification is provided in this research with a structural break test in the currency series that followed the January 15th, 2015 currency dis-intervention, when the then freed currency prices drastically initiated a search toward its fundamental values. In our study, we analyze municipal bonds premiums rather than government bonds premiums. Some studies claim that both premiums are affected by similar events and factors, especially in the 4 weeks after they were initiated. For example, Knezevic et al. (2021) claim that in the case of the event study concerning sudden decrease in the government bond yield primarily increases the municipal bond yield spread. However, this event will be offset after 4 weeks due to the municipal bond yield spread being lower than it was in the beginning.

In the context of this paper, we identify that the SNB's constant intervention in the Swiss franc rates for the 2011-2015 period led to its currency value, to the euro, being priced at levels significantly different from its fundamental values. The aim of this study is to identify the effects of currency price distortions on the municipal bond spread in Switzerland. The objective of this research is specifically aimed at determining whether the spread has indeed widened after the currency shock and if so, to determine the percentage of change in the premiums after the currency shock. In this paper, the dis-intervention in the Swiss franc rates of 2015 will be used as a quasi-natural experiment, to explore whether a "no government intervention" in the foreign exchange markets policy may have impacted the spreads and changed the default, liquidity, and/or maturity premiums of municipal bonds in Switzerland. This study uses the daily trading settlement data of municipal bonds in the Swiss inter-bank bond market as samples from January 2012 to January 2018 (three years before and three years after the currency shock). The 
study uses a two-stage least squares method to derive its conclusions. More details of the model have been provided in the data and methodology section. The following questions are addressed: Does a raise in the local currency prices contribute to a widening of the municipal bond spreads? Do changes in the currency price levels make a long-run impact on the municipal bond spreads? We used an instrumental variable approach in our study to answer these questions. The following should be noted in respect to the current practical knowledge: firstly, our results may have policy implications. For example, since they may imply that if policymakers wish to reduce the relative cost of financing for state and local government investments, all efforts to reduce transaction costs and improve liquidity will have no significant impact on borrowing costs, and all efforts to lower default risks by municipalities would be wasted. Secondly, this area is insufficiently researched (especially in the case of municipal bonds with price distortions), and any additional study represents a contribution to literature and current theoretical knowledge.

In the remainder of this paper (after the $1^{\text {st }}$ section), we review different arguments concerning the effects of price distortions on municipal bond spreads. The second section discusses and reviews the literature on such effects, including studies with the issues of default premiums, liquidity premiums, and foreign exchange premiums. As part of this section, we also focus on applied mythology in similar studies. The third section explains the applied methodology with the cross-sectional instrumental variables model and the instrumental variables with the panel data model. The results are reported in section four, and the discussion and implications are presented in section five. Section six contains the conclusion.

\section{Literature review}

Most of the academic literature on municipal bonds research the tax effects as the top feature in this market. Since most municipal bonds are exempt from local and state taxes, the pricing of their cash flows relative to treasuries and corporate bonds has been extensively studied. Miller (1977) sets out the theory behind the relationship between debt and taxes; while Trzcinka (1982) tests the theories of the relationship between taxexempt and taxable interest rates, whereby applying the Miller hypothesis predicts that the tax-exempt rate is $52 \%$ of the taxable rate in the US, while the institutional demand hypothesis forecast a volatile relationship. His results favor the Miller hypothesis, in that the marginal tax rates are found to be close to Miller's predicted $48 \%$ and the marginal tax rate seems to be stable over time. Ang et al. (2010) find that after computing the tax payments, market discount bonds, which bear income tax liabilities, usually trade at yields nearly 25 bps higher than comparable municipal bonds not subject to any taxes, and that the high sensitivities of municipal bond prices to tax rates can be attributable to special characteristics of this market's players, such as: individual retail traders, dominating dealers and other market power institutions. A Longstaff (2011) study found that the marginal tax rate embedded into the short term tax-exempt municipal rates is able to identify an average marginal tax rate during a particular period of $41.6 \%$, and that marginal tax rate is significantly positively related to the returns in the stock and bond markets. Furthermore, he argues that the risk premium linked to the marginal tax rate is negative, in line with the contra-cyclical nature of after-tax fixed-income payments 
that tend to increase during hard times of the economy, as individual's income and the average marginal tax rates applied to those payments decline. Another point raised by Babina et al. (2015) is that most states exempt only local bonds from state income tax, leading to home bias and imperfect risk sharing.

Wang et al. (2008) claimed that municipal bond yields are frequently higher than expected relative to yields on treasury bonds. Theoretically, returns on taxable and municipal bonds with the same maturity and comparable risk characteristics, should be equal for investors, after paying tax on taxable bonds (Wang et al. 2008; Vukovic et al. 2020b). However, the same authors (2008) found opposite results in their studies, in many cases in US bonds markets. Especially in the case of long-maturity (municipal bonds were giving higher yields). Their explanation is based on the institutional demand hypothesis in the works of Galper and Peterson (1971), Kimbal (1977), and Fama (1997). Previously, Green (1993), and Green and Odegaard (1997), found similar results due to the reason that dealer arbitrage activities in the government bond market significantly reduce the impact of taxes on long-maturity taxable bond prices. Shoven and Sialm (2004) found similar results comparing returns on municipal and taxable bonds in models of optimal asset locations and allocations for risk-averse investors saving for retirement. However, they found that yields on municipal bonds are higher in comparison to after-tax taxable bonds only in the case of high- and medium-income individuals. The reason may lie in the fact that municipal bonds are attractive to high-net-worth individuals (Ang et al. 2010). According to Ang et al. (2010), individuals held 70\% of all outstanding municipal bonds in 2007.

Low liquidity is also an important factor in the pricing on the market (Vukovic and Prosin 2018). Municipals trade on an over-the-counter basis and the tax exemption attracts retail investors primarily, resulting in high transaction costs due to search frictions and broker/dealer market power. Yield spreads of municipals relative to treasuries also adjust with the asymmetric speed in rising and falling markets as per results from Green et al. (2010). Another explanation by Novy-Marx and Rauh (2011) consider the challenging conditions related to public pensions as influencing the liquidity of municipalities. Longstaff (2011) also studied the credit/liquidity spread in 1-week tax-exempt rates, finding that it is a very small component compared to the marginal tax rate. Wang et al. (2008) found that liquidity plays a secondary role to default risk in municipal bond pricing. In contrast, Ang et al. (2010) found that liquidity accounts for $74 \%$ of the average municipal bond spread. Jiang (2019) found that for the Chinese market, the liquidity risk of municipal bonds is a key factor that influences the yield spread, and the marginal effect on the yield spread from the liquidity risk is around 4.6 bps. In Wang et al. (2008), the relative yields of municipality bonds were examined with a generalized model that includes liquidity as a state factor. These authors used a unique transaction dataset to estimate the municipal bonds liquidity risk and the effects on bond yields. According to their findings, a significant fraction of the maturity spread between long- and shortmaturity municipal bonds is caused by the liquidity premium.

However, liquidity is not the only risk affecting municipal bonds. Previously, several studies (like Hempel 1972; Zimmerman 1977; Trzcinka 1982; Dammon et al. 2004; Wang et al. 2008; Green 2007; Green et al. 2010; Cuny 2016; Vukovic et al. 2020b) found that default risk on municipal bonds could be higher than the default risk of corporate bonds 
in the same rating class. The reason is due to the unique features of municipal assets and less predictable political processes. In recent studies, Schwert (2017) finds that default risk accounts for $74-84 \%$ of the average municipal bond spread over the period 19982015 after adjusting for the tax exemption. The average default spread of around 100 bps and the particularly low historical default occurrences would suggest a default risk premium larger in magnitude than the risk premium estimates in the corporate bonds market. Investors in the municipal bonds receive between 78 and 126 bps of taxableequivalent benefit per each basis point of expected default loss. The author shows that default risk plays a big role relative to the observed degree of default because of a highrisk premium and finds that the role of liquidity is not as large as it could be inferred from other studies on transaction costs in the municipal bonds market. It seems that the liquidity portion of the spread is affected by the expected trading costs and the expected trading intensity, and the necessity to liquidate the bonds at certain required times. The typical investor in this market is a buy-and-hold (long-term) investor, for what trading intensity is usually low, hence a small liquidity discount. During the crisis from 2007 to 2009, Wei and Yue (2020) found that the value of a liquidity backstop is about 14.5 basis points per annum. These authors used the calibrated model on municipal bond markets to test the effectiveness of liquidity backstops. Similar effects of the crisis were tested in the studies of Vukovic et al $(2019,2021 \mathrm{a}, \mathrm{b})$ and Vukovic et al (2020a) where authors find a strong influence on interest rates $(2019,2021 \mathrm{a}, \mathrm{b})$ and portfolio position of the investor (2020a).

Fabozzi (2007) suggests that the municipal bonds, such as the treasuries, under normal economic states, may not offer any additional compensation to the investor from one additional year for the maturity of the bond in the long portion of the yield curve. Therefore, the average investor should not be rewarded much for investing in an 11-year municipal bond versus a 10-year one, to gain maturity of the same bond. Depending on the approach used to decompose the set of premiums though, it may be possible to identify the weight and magnitude of each additional year of maturity of bonds. The models used in this research may offer a ballpark figure of this component for the Swiss municipal bonds. Manchester and Davies (2009) suggest that continued foreign investment in treasury bonds would continue to drop the yields on them relative to municipal bonds. Therefore, the treasuries after-tax yields would decrease, turning lower than the observable un-taxed yields of municipal bonds in the long run. Then, local investors would have a higher incentive to purchase municipal bonds relative to treasuries, while foreign investors would have an incentive to increase their purchases of treasuries. This indicates a possible market segmentation in the government-issued bonds market as a result of the tax benefits from investing in municipal bonds for local investors on one side, while foreign purchases increase in the treasuries market on the other side. In the study of Vukovic et al. (2020b), market segmentation is even more emphasized at the regional level. The authors used Standard and Poor's data to test US municipal bond market attractiveness. According to their model and findings, investors (domestic and foreign) are more interested in the markets where municipalities offer portfolio investment (municipal bonds cases). They show in their empirical model that an investment with the duration of 4.6 years on a 5 -year municipal bonds portfolio with appropriate immunization will secure good returns for investors. 
From the methodological point of view, the effects of the price distortions on the bond spread can be found in several studies. Bleaney and Veleanu (2021) note the risk spillovers between EU area treasury bond spreads and corporate bonds in the EU monetary zone. Authors used regression analysis to show that there is significant risk transfer after decomposing the treasury bond spread into a default risk and a currency redenomination risk (the risk when a euro asset is redenominated into a devalued legacy currency). Moreover, according to the results of their study, currency redenomination risk has been a significant factor in pricing. However, there are also studies that have analyzed the effects of price distortions on the bond spread during global shocks. For example, Balli (2009) finds that global shocks have a greater impact on bond spreads in different European bond markets than it does on specific market risk. For this analysis, the author used a regression model to note that the level of the default premiums of the government bond was mostly affected by global events. Knezevic et al. (2021) analyzed five-year zerocoupon municipal bond yields and government bonds in Sweden to test the influence of monetary policy on their price distortions. The authors used bivariate vector autoregressive models for studying that dynamic relationship, and used the Dickey-Fuller and the KPSS tests for testing their hypotheses. According to their results, there was a difference in pricing in a short period of time for both kinds of bonds. Due to this event, when a monetary policy influence on a government bond yield decreases, the municipal bond yield will increase at the same time. However, after a short period, the return on the municipal bond will be lower and this relationship will revert to the behavior it showed in the beginning. Jiang (2019) uses the two-stage least squares method to solve the endogeny problem between liquidity and yield spread after government intervention in China. According to the author's results, reduction in government intervention has affected the reduction liquidity premium level of municipal bonds. The two-stage least squares method proved to be an appropriate method for the study. Originally derived from the Harris elastic method (1990), Jiang (2019) applies the two-stage least squares method with the further testing of instrumental variables, such as a robust Durbin-WuHausman Test to test the endogeneity of the variables; the explanatory power of instrumental variables, with the limited information maximum likelihood method; and the robustness of the two-stage least squares method regression results (generalized method of moments).

Studies related to the Switzerland municipal bonds are almost untouched and hence the present study attempts to identify the effects of currency price distortions on the municipal bond spread in Switzerland. By conducting this analysis, we contribute to the literature in three ways. First, we provide further empirical evidence on the relationship between price distortions on the municipal bond premiums considering how the exchange rate affects the liquidity and default premiums of municipal bonds. Given that this area has been very little studied, any further contribution to the literature on this issue is substantial. Second, our results contribute to policymakers (effects of monetary policy) and investors (asset pricing, market microstructure, financial intermediation, etc.) for a better understanding of the effects of price distortion on municipal bonds. Third, we test another methodology, or more precisely another regression analysis, that contributes to understanding which methods are most effective in analyzing such timeseries samples. 


\section{Data and methodology}

This research takes the daily trading settlement data of municipal bonds in the Swiss inter-bank bond market as samples. The data ranges from January 2012 to January 2018, that is, three years before and three years after the currency shock. This data only includes the municipal bonds that were still outstanding from the end of the range between January 2012 and January 2018 and avoiding duplication of maturities by a municipality. A total of 26 bonds are considered in this data. All data have been obtained from the EIKON Refinitiv terminals.

\section{Empirical model}

In our empirical model, two approaches are used to decompose the municipal bonds spreads into liquidity, maturity, and default risk premiums. The first approach is the cross-sectional instrumental variables model, and the second approach is the instrumental variables with panel data model. We found the motivation to use this model in the study of Harris (1990). Harris' elasticity model is used to analyze the liquidity elasticity provided by banks, market makers, and trading firms (or liquidity providers). However, this two-stage least squares method is also very suitable for testing default premiums and price distortions. Jiang (2019) notes that the two-stage least squares method is very appropriate for the price distortions and bonds premiums. In our study we use similar steps in the methodological approach. However, we also analyze the structural breaks (Bai-Perron test) to determine their existence in bond distortions. Applying this test will influence the greater novelty of our study. Further, we use Durbin-Wu-Hausman tests for each decisive model to verify endogeneity issues, and the Lagrangian Multiplier test and the Cragg-Donald Wald F statistic to confirm the relationship of instrumental and endogenous variables.

For the municipal bond spread, we find motivation in the study of Schwert (2017). The yield spread between municipal bonds and risk-free bonds depends primarily on the likelihood of default, compared to the treasury bonds. Two additional factors also contribute to municipal bond yield spreads, though. First, municipal bonds are traded over the counter and on a "buy and hold" basis for whatever significant costs may be accounted for in attempts to sell them in the secondary markets (Schwert 2017). Second, additional years to maturity may add risk to the investors for which higher rates must be offered on longer maturity bonds to compensate investors. These two factors suggest that, in addition to default risk, liquidity and term to maturity risks influence the pricing of municipal bonds. Accounting for these considerations, the municipal bond spread can be expressed as follows:

$$
R m_{i, t}-R f_{t}=\alpha_{i}+\beta_{i} \text { dfault }_{i, t}+\gamma_{i} \text { liqdty }_{i, t}+\delta_{i} \text { matur }_{i, t}+\varepsilon_{i, t}
$$

where $R m_{i, t}-R f_{t}$ is the municipal bond to risk-free rate spread, that depends on the default (dfault), liquidity (liqdty), and maturity (matur) premiums, for each individual municipal bond $i$ at any given moment $t$.

The risk-free rate, on the other hand, might be influenced by additional factors in any given period that may affect the magnitude of the municipal bond spread. Under the Swiss market characteristics, one of these factors might affect the spread magnitude 
due to the currency rate fluctuations. As we progress in this section, appropriate tests to prove the relevancy of the currency rate in this setup will be provided. In this study, we establish that the dynamics in the municipal bonds yield spread in Switzerland could be influenced by the dynamics in the currency price through its impact on the government bond yields. To establish this causality, we use the instrumental variables approach as our identification strategy, in which we assume that the currency price changes may have an impact on the municipal to government bond spread by the influence it has on the latter. Thus, a two-stage least squares method is used to solve the endogeneity issue between Spread to Benchmark and Treasury Yields, and links the currency prices with the spread.

Stage 1: $\quad t_{-}$yield $_{t}=\pi_{0}+\pi_{1}$ currency $_{t}+v_{t}$

Stage 2: bnchmrksprd $_{i, t}=\beta_{0}+\beta_{1} t_{-}$yield $_{t}+\beta_{2}$ liqdty $_{i, t}+\beta_{3}$ matur $_{i, t}+\beta_{4}$ rank $_{i, t}+u_{i, t}$

In the first stage, the variable currency $_{t}$ represents how the endogenous variable $t_{-}$yield $_{t}$ is affected by changes in the currency, so that the control variable is currency $y_{t}$ Whereas, in the second stage the bnchmrksprd $_{i, t}$ dependent variable measures the difference of a municipal bond $i$ yields to those of the same maturity treasury bonds; the liqdty $_{i, t}$ variable measures the bond liquidity by how often a particular municipal bond $i$ trades, for which we convert the number of missing values in our data as a non-trading date, so that the more non-trading dates, the less liquid the municipal bond is in the time series. ${ }^{1}$ For simplicity, this study assumes that there are only two types of municipal bonds: a liquid bond, that trades every day and a not-as-liquid bond that may not trade on some days. To accomplish this, simply assign a number 1 to each day the bond trades, and 0 when it does not. The matur $_{i, t}$ variable measures the length to maturity of the particular municipal bond in years from the time of the experiment. The $\operatorname{rank}_{i, t}$ variable is a dummy variable that measures the default risk by assigning the value of 1 if the municipal bond has the maximum AA+ rating, and a value of 0 if it holds AA through AA-, considering that the data used in this study only shows these ratings for the municipals that trade in the Swiss market.

Notice that in this model however, other variables or controls have been omitted for simplicity, as the scope of this study does not aim for the best or the goodness of fit of the models proposed. That is, the intention is to estimate changes in the structure of the spread, and not how well the model works. The process starts by obtaining the structure of the average premiums before the currency shock (16jan2012-15jan2015 period), then after the shock (16jan2015-15jan2018 period), and finally for the whole six-year period (16jan2012-15jan2018 period), using the currency shock as instrument. Each scenario is compared with the fixed effects approach for an instrumental variable panel data as well, for which we obtain six estimators for each variable to interpret the results. All variables statistics are summarized in Table 1.

To check the validity of the instrumental variables requested to build control functions to adjust for endogeneity in the model, we use the Lagrangian Multiplier test introduced by Breusch and Pagan (1980). The validity test is especially important in ordinary least

\footnotetext{
${ }^{1}$ Since municipal bonds trade OTC in Switzerland, it would not be accurate to use the bid/ask spread and/or the volumes data, rather using a trade-to-no-trade is preferred to get valid results.
} 
Table 1 Summary descriptive statistics all variables

\begin{tabular}{lllllllll}
\hline Variable & Obs & Mean & SD & Min & Max & Variance & Skewness & Kurtosis \\
\hline chf_eur & 40,716 & 0.8698 & 0.0525 & 0.7946 & 1.0123 & 0.0028 & 0.3316 & 1.5444 \\
t_yield & 39,104 & -0.1698 & 0.2848 & -0.9340 & 0.4130 & 0.0811 & -0.3504 & 2.1269 \\
bnchmrksprd & 35,177 & 47.3347 & 16.8589 & -0.07 & 172.46 & 284.2220 & 2.8286 & 16.4134 \\
matur & 40,716 & 15.1154 & 7.1969 & 5 & 28 & 51.7957 & 0.3521 & 1.7297 \\
Rank & 40,716 & 0.5769 & 0.4941 & 0 & 1 & 0.2441 & -0.3114 & 1.0970 \\
Liqdty & 40,716 & 0.8639 & 0.3429 & -0.0705 & 1 & 0.1176 & -2.1230 & 5.5070
\end{tabular}

. sum chf_eur t_yield bnchmrksprd matur rank liqdty

This table presents the dataset key statistics. Symmetric distributions for coefficient of skewness zero, negative coefficients skewed left and positive skewed right. Smaller kurtosis coefficients for flatter distributions (fat tails), assuming normal distributions have a coefficient of kurtosis of 3. Source: Own estimations

squares models due to the correlation between an independent variable of an econometric model and the conditional expectation of the error member on the independent variable not being zero. In econometric literature, this problem is called the endogeneity problem. According to Breusch and Pagan (1980), the model assumes that for the sample $N$ with a known distribution, there is an unknown number of set $K$ for parameters $\theta=\left(\theta_{1}, \ldots \theta_{k}\right)$, for the possibility $L(\theta)$, Lagrangian function is:

$$
L(\theta)+\sum_{j=1}^{p} \lambda_{j} h_{j}(\theta)
$$

a distinguishing expression where $\theta$ is an unknown parameter and $\lambda_{j}$ is the Lagrange multiplier, with $\tilde{\theta}$ and $\tilde{\lambda}$ as solutions of the 1st order condition:

$$
\begin{aligned}
& \tilde{D}+\tilde{H} \tilde{\lambda}=0 \\
& \text { for } \tilde{h}_{j}(\theta)=0 \text { and for } j=1, \ldots, p
\end{aligned}
$$

where

$$
\begin{aligned}
& \tilde{D} \text { is the }(K \times 1) \text { vector }\left\{\frac{\partial L}{\partial \theta_{1}} \widetilde{(\theta)}\right\}, \\
& \tilde{H} \text { is the }(K \times p) \text { matrix }\left\{\frac{\partial L}{\partial \theta_{1}} \widetilde{(\theta)}\right\},
\end{aligned}
$$

and $\tilde{\lambda}$ is a $(p \times 1)$ vector of Lagrange multipliers.

For checking predictor variables in our regression model, we use the Durbin-WuHausman specification test. According to this test, the OLS estimators will fail in situations where endogenous regressors are present. This is due to the assumption that there is no correlation between predictor variables and the error term. Moreover, there is an assumption in the OLS regression that all independent variables are uncorrelated with the error term (Gujarati et al. 2012). In the two-stage OLS regression analysis, first-stage regression is:

$$
x_{i}=I \alpha+Z v+\delta_{i}
$$


where $x_{i}$ presents the vector of the endogenous variable $i, I$ is the matrix for an instrumental variable, $Z$ is the matrix of covariate, and $\delta_{i}$ is the error term. The 2 nd stage of regression analysis is:

$$
y_{i}=\hat{x}_{i} \beta_{i}+Z \beta+\mathrm{e}
$$

where $y_{i}$ presents the vector of the outcome variable, $\hat{x}_{i}$ is the vector of predicted values of $x_{i}$ according to the first-stage regression, $\beta_{i}$ is a parameter that estimates the causal effect of the endogenous variable on the outcome variable, $Z$ is the matrix of covariate, $\delta_{i}$ is the error term and $\beta$ is the slope $Z$.

For the testing relationship between variables during the observed period, we use the Bai and Perron $(1998,2006)$ structural break model. In this way, we check whether variations in factors beyond the model affect changes in the fundamental relationship between the variables in the model. The Bai-Perron model describes these occurrences exactly by embedding unexpected and enduring changes in the model parameters. The model considers the next multiple structural break model with $m$ breaks ( $m+1$ regimes):

$$
\begin{aligned}
& y_{t}=x_{\beta}^{\prime}+z_{t}^{\prime} \delta_{1}+\mu_{t}, \quad \mathrm{t}=1, \ldots T_{1} \\
& y_{t}=x_{\beta}^{\prime}+z_{t}^{\prime} \delta_{2}+\mu_{t}, \quad \mathrm{t}=T_{1}+1, \ldots T_{2} \\
& \ldots \ldots \ldots \ldots \ldots \ldots \ldots \ldots \ldots \ldots \ldots \ldots \ldots \ldots \ldots \ldots \ldots \\
& y_{t}=x_{\beta}^{\prime}+z_{t}^{\prime} \delta_{m+1}+\mu_{t}, \quad \mathrm{t}=T_{m}+1, \ldots T
\end{aligned}
$$

where $y_{t}$ presents the dependent variable at time $\mathrm{t}$, as a linear combination of regressors with both time invariant coefficients $x_{t}$ and $z_{t}, \beta^{1}$ and $\delta_{j}($ for $j=1, \ldots, m+1$ ) are observed as equivalent vectors of coefficients and $\mu_{t}$ is the break term at time t. The parameters $T_{1} \ldots T_{m}$ are the unknown breakpoints that are estimated when $\mathrm{T}$ observation is available. The main purpose of this expression is to approximate unknown regression coefficient and break dates' $\beta, \delta_{j}$, and $T_{1} \ldots T_{m}$ when T observations $y_{t} x_{t}$ and $z_{t}$, are available. We consider that Bai and Perron $(1998,2006)$ structural break model is important to include in this study due to different policy changes and economic factors being able to affect changes of variables over time $T$. Moreover, failing to recognize structural breaks will lead to an invalid conclusion because of erroneous driving mechanisms of changes in data.

\section{Results}

Through a correlations analysis, it is possible to confirm our expectations that there is a high correlation between the movements of the currency and the treasury bond yields as shown in the first column of Table 2. This goes in line with the fact that the higher demand for Swiss treasuries lowers their yield while increasing the value of its currency. In this same column, notice the absence of correlations between the currency instrument and the matur and rank variables, as well as in the second column that absences of correlations are true with the $t$ yield variable. Another key finding in this column is the existence of some correlation between the currency behavior and the liqdty variable. In the third column, it is possible to view the positive correlation between the benchmark spread and the maturity of the bonds, implying a higher spread for longer maturity in line with financial theory. In this same column, it is also possible to view the negative 
Table 2 Correlations results

\begin{tabular}{lcccccc}
\hline & chf_eur & t_yield & bnchmrksprd & matur & rank & liqdty \\
\hline chf_eur & 1.0000 & & & & \\
t_yield & $-0.7880^{*}$ & 1.0000 & & & \\
& 0.0000 & & & & \\
bnchmrksprd & $-0.0298^{*}$ & -0.0113 & 1.0000 & & \\
& 0.0000 & 0.0338 & & & \\
matur & 0.0000 & 0.0000 & $0.1476^{*}$ & 1.0000 & & \\
& 1.0000 & 1.0000 & 0.0000 & & & \\
rank & 0.0000 & 0.0000 & $-0.3223^{*}$ & $-0.0187^{*}$ & 1.0000 & \\
& 1.0000 & 1.0000 & 0.0000 & 0.0002 & & \\
liqdty & $0.2453^{*}$ & $-0.1815^{*}$ & 0.0150 & $-0.1056^{*}$ & 0.0157 & 1.0000 \\
& 0.0000 & 0.0000 & 0.0049 & 0.0000 & 0.0015 & \\
\hline
\end{tabular}

***, *** ${ }^{*}$ Coefficients are significant at the $1 \%, 5 \%, 10 \%$ level. Source: Own estimations .pwcorr chf_eur t_yield bnchmrksprd matur rank liqdty, sig star(0.001)

Table 3 Regression results

\begin{tabular}{lclllll}
\hline Variable & MGIV2SLS & MGIVFE & M1IV2SLS & M1IVFE & M2IV2SLS & M2IVFE \\
\hline t_yield & $2.5159^{* * *}$ & $2.5107^{* * *}$ & $33.8708^{* * *}$ & $32.1012^{* * *}$ & $-17.8684^{* * *}$ & $-18.5987^{* * *}$ \\
matur & $0.3109^{* * *}$ & (omitted) & $0.4575^{* * *}$ & (omitted) & $0.1871^{* * *}$ & (omitted) \\
rank & $-10.7560^{* * *}$ & (omitted) & $-9.2982^{* * *}$ & (omitted) & $-11.4888^{* * *}$ & (omitted) \\
liqdty & $48.1404^{* *}$ & $32.5865^{* *}$ & (omitted) & (omitted) & $49.8798^{* *}$ & $34.3906^{* * *}$ \\
_cons & 1.3050 & 15.2251 & $44.5415^{* * *}$ & $45.8749^{* * *}$ & -6.1609 & 5.2306 \\
\hline
\end{tabular}

This table displays the coefficients of the variables in the models proposed. The models considered are the Instrumental Variables, Two Stage Least Squares Cross-Sectional (IV2SLS) and the Fixed Effects (IVFE) approaches, tested for the entire data period (16jan2012-15jan2018), before the currency shock (16jan2012-15jan2015) and after the currency shock (16jan2015-15jan2018) periods, labeled MGIV2SLS, M1IV2SLS, M2IV2SLS, MGIVFE, M1IVFE and M2IVFE, respectively. All approaches use the currency price as control variable

$* * * * * * *$ Coefficients are significant at the $1 \%, 5 \%, 10 \%$ level. Source: Own estimations

${ }^{*} p<0.05 ;{ }^{* *} p<0.01 ;{ }^{* * *} p<0.001$

correlation between the spread and the rank variable, implying a smaller spread for a lower default risk (higher credit rating). Finally, these results conclude that, for the data used in this study, this set of variables are relevant as instruments.

The regression results, estimated by the two-stage least squares approach, are shown in Table 3. Column MGIV2SLS shows the results for the empirical model estimation for the whole six-year period, while columns M1IV2SLS and M2IV2SLS show the results for the same model estimation for the first period and second periods, respectively. Column MGIVFE shows the results for the empirical model estimation for the whole sixyear period with fixed effects, while columns M1IVFE and M2IVFE show the results for the first and second periods with fixed effects, respectively. ${ }^{2}$ In all of these approaches, the variable currency has been used as the instrument in the first stage for the endogeneity of the treasury yield variable.

\footnotetext{
2 The variables matur and rank in the panel data approach are omitted due to the co-linearity between these variables We have used the 2SLS approach to overcome this issue.
} 
The regression results show high statistical significance for most variables. Suppose, we compare a 10-year, highly liquid, and highest-rated municipal to a 10-year treasury bond that yields $-0.382 \%,{ }^{3}$ using the coefficients in this table, the table would suggest an expected spread before the shock of $26.88 \mathrm{bps}$, and an expected spread of $40.93 \mathrm{bps}$ after the shock, in line with our expectations that the spread has, in fact, widened an average of 14 bps after the currency dis-intervention.

Column MGIV2SLS shows that for the six-year period, the matur coefficient is 0.3109, while the rank coefficient is - 10.7560. In columns M1IV2SLS and M2IV2SLS, these coefficients are $0.4575,0.1871$ and $-9.2982,-11.4888$, respectively. Although the maturity premium seems small relative to the other premiums, these results show that the maturity premium for each additional year of the municipal bond maturity has decreased 59.10\% for the period after the currency shock, but accounting for just $4.57 \%$ of the spread, from a previous $17 \%$. Therefore, one more year in the maturity of the bond would mean only a small extra yield to the investor in the long portion of the yield curve. Interestingly though, there is evidence to conclude that the default risk premium, which accounted for $34.59 \%$ of the spread before the shock, has increased $23.56 \%$ in absolute value, and is still counting to $28.07 \%$ of the now wider spread, after the currency shock. ${ }^{4}$ Thus, the change of one level in the scale to the highest credit rating would translate into a reduction of $11.4888 \mathrm{bps}$ in the spread. Should the 10-year treasury yields be around $-0.382 \%$, a one-scale improvement in the municipal bond default risk would translate into a $28 \%$ reduction from a 52.41 bp to the 40.93 bp spread. Furthermore, the $23.56 \%$ increase in this premium after the currency shock suggests the importance of its sensitivity to currency price distortions. The analysis of the liquidity premium is somewhat unclear though, as the results of the models seem inconclusive. In this respect, the liquidity premium may be affected by other variables such as financial market characteristics, trading platforms, transaction costs (Green et al. 2010), tax exemptions, and the particular type of investors in this market, such as pensions funds (Novy-Marx and Rauh 2011) and large institutions. Nonetheless, all these factors lead us to believe that the municipal bonds market seems to be rather non-liquid compared to the Swiss treasury bonds market.

Although we have identified the magnitudes and changes after treatment of at least the maturity and default premiums, these changes are counter directional to the change in the spread. That is, the increases in both premiums reduce the spread after the treatment instead of widening it. What, then, has caused the widening of the spread after the currency shock? A possible answer could be the price differentiation from the market segmentation (Manchester and Davies 2009) because of the tax benefits from investing in municipal bonds for local investors, leading to (inverted) home bias and imperfect risk sharing as Babina et al. (2015) have suggested. Therefore, the higher demand for Swiss treasuries from foreign investors targeting this asset, as a reaction to the currency disintervention, while showing a light appetite for the municipals (as these investors would not benefit from the tax exemption for local investors) may have widened the spread.

\footnotetext{
${ }^{3}$ All these inferences were made assuming treasury yields in the range of [-0.281, -0.483$]$, that is, yields registered in the sessions near the currency shock.

${ }^{4}$ Notice that in the default risk premium, since the coefficient has a negative sign, an increase in this premium implies a decrease in the spread.
} 
Table 4 Instrumental variables tests

\begin{tabular}{|c|c|c|c|c|}
\hline \multicolumn{5}{|c|}{ Durwin-Wu-Hausman test } \\
\hline \multicolumn{5}{|c|}{ Tests of endogeneity } \\
\hline \multicolumn{5}{|c|}{ Ho: variables are exogenous } \\
\hline \multirow[t]{2}{*}{ MGIV2SLS } & Robust & Score & $\operatorname{chi} 2(1)=152.062$ & $(p=0.0000)$ \\
\hline & Robust & Regression & $F(1,35,100)=154.077$ & $(p=0.0000)$ \\
\hline \multirow[t]{2}{*}{ M1IV2SLS } & Robust & Score & $\operatorname{chi} 2(1)=472.497$ & $(p=0.0000)$ \\
\hline & Robust & Regression & $F(1,15,652)=180.464$ & $(p=0.0000)$ \\
\hline \multirow[t]{2}{*}{ M2IV2SLS } & Robust & Score & $\operatorname{chi} 2(1)=5.89291$ & $(p=0.0152)$ \\
\hline & Robust & Regression & $F(1,19443)=5.87356$ & $(p=0.0154)$ \\
\hline
\end{tabular}

This table presents whether there is endogeneity in the variables included in the models selected. The large Chi2 and $\mathrm{F}$ values reject the null hypothesis that all variables in the models are exogenous (zero $\mathrm{p}$-values state endogenous variables). All approaches use the currency price as control variable. Source: Own estimations

Table 5 First-stage regression summary statistics

\begin{tabular}{llll}
\hline Model & Variable & R-sq & Adjusted R-sq \\
\hline MGIV2SLS & t_yield & 0.6224 & 0.6223 \\
M1IV2SLS & t_yield & 0.3206 & 0.3205 \\
M2IV2SLS & t_yield & 0.065 & 0.0648
\end{tabular}

.estat firststage

In this table, the column Robust $F$ Value is an $F$ statistic for the significance of the instruments coefficients. Its $p$-value is presented in the Prob $>\mathrm{F}$ column. If the $\mathrm{F}$ statistic is not significant, then the instruments have no significant explanatory power for $t \_y i e l d$ after controlling for the effect of chf_eur. Source: Own estimations

Table 6 Instrumental variables identification tests. Source: Own estimations

\begin{tabular}{|c|c|c|c|c|c|c|c|c|}
\hline \multirow{2}{*}{\multicolumn{5}{|c|}{$\begin{array}{l}\text { Underidentification test (Anderson canon. corr. LM } \\
\text { statistic): } \\
\text { Ho: underidentification of instrumental variables }\end{array}$}} & \multirow{2}{*}{\multicolumn{4}{|c|}{$\begin{array}{l}\text { Sargan statistic (overidentification test of all } \\
\text { instruments): } \\
\text { Ho: overderidentification of instrumental variables }\end{array}$}} \\
\hline & & & & & & & & \\
\hline MGIV2SLS & $2.20 \mathrm{E}+004$ & Chi-sq P-val & $=$ & 0.0000 & (equation exactly identified) & Chi-sq P-val & $=$ & N/A \\
\hline M1IV2SLS & 4993.040 & Chi-sq P-val & $=$ & 0.0000 & (equation exactly identified) & Chi-sq P-val & $=$ & N/A \\
\hline M2IV2SLS & 1264.148 & Chi-sq P-val & $=$ & 0.0000 & (equation exactly identified) & Chi-sq P-val & $=$ & N/A \\
\hline
\end{tabular}

This table presents large Chi2 values in the Instrumental Variables Underidentification test, rejecting the null hypothesis that there are less relevant instruments in the models than endogenous variables. The zero $p$ values state no underidentification of instruments. In the Overidentification test, it is not possible to obtain results as the model is exactly identified. That is there is one endogenous variable $t \_y i e l d$ and one instrument chf_eur

For the verification of whether there are endogeneity problems between the municipal bond yield spread and the variables considered in the models, this study performs the robust Durbin-Wu-Hausman tests for each decisive model. The results of the endogenous tests are shown in Table 4.

These results display very large chi2, and p-values of zero for the longest and the first period models, and even though the p-values in the last model are not completely zero, they are close enough, considering that this segment is part of the longer period model. Therefore, these results strongly reject the null hypothesis that all explanatory variables are exogenous.

To verify the explanatory power of the instrumental variables, the correlation test of the first-stage regression is performed. The results in Table 5 show that the robust $F$ 
Table 7 Weak instrumental variables tests

\begin{tabular}{llll}
\hline & MGIV2SLS & M1IV2SLS & M2IV2SLS \\
\hline $\begin{array}{l}\text { Weak identification test (Cragg-Donald Wald F } \\
\text { statistic) }\end{array}$ & $5.80 \mathrm{E}+004$ & 7328.989 & 1351.68 \\
Stock-Yogo weak ID test critical values: & 10\% maximal IV size & & 16.38 \\
& 15\% maximal IV size & 8.96 \\
& 20\% maximal IV size & 6.66 \\
& 25\% maximal IV size & & 5.53 \\
\hline
\end{tabular}

This table presents large C-D Wald F statistics on all models, and lower S-Y weak ID test critical values, rejecting the null hypothesis that the instruments in the models are weak. If any of the critical values were larger than the C-D Wald F values, then there would be at least one weak instrument in the models. Source: Own estimations

values for all models used are large enough to strongly reject the null hypothesis that the coefficients of the instrumental variables are zero, even at the 1 percent level. An F statistic value less than 10 may indicate weak instruments, which is not the case here.

The Lagrangian Multiplier test is performed to confirm whether there are fewer instrumental variables than endogenous ones used in these models. The results in Table 5 show that for all the models, this statistic is large enough to strongly reject the null hypothesis that the models are under-identified. Moreover, the Sargan statistics on the right-hand side of Table 6 confirm that there is no overidentification of instruments in either model, as the equation proposed is identified exactly. Thus, the inclusion of the currency variable is plausible using the first test and should not be excluded, according to the results of the second test.

Although the correlation results indicate that the variables included in the models are relevant as instruments, Table 7 also proves that none of the critical values come close to the Cragg-Donald Wald F statistic. This confirms that none of the instruments used in this study are weak. Had there been any weak instruments, there would be a low value of $\mu^{2}$ resulting in a low value of $\mathrm{F},{ }^{5}$ which is clearly large enough for all three models.

A structural break is an event that abruptly changes a time series at a given moment in time. This sudden change may affect the mean or substantially change other parameters of the process that generate the series. Being able to detect the exact moment when the structure of the time-series shifts gives us insights into the problem we are studying. Structural break tests help us determine when, and if, there is a significant change in our data. As the currency shock of January 15th, 2015, seems quite abrupt, it may not have necessarily generated important long-run changes in the time series. However, tests for structural breaks prove otherwise in this particular event. Table 8 displays a very large Wald F statistic, identifying an estimated break at the 784th date in the time series, which is exactly on January 15th, 2015. Thus, this date's events caused a prominent structural break in this variable.

\footnotetext{
${ }^{5}$ In our model: $X=Z \Pi+W \delta+v$, where $X$ is bnchmrksprd, $Z$ is the endogenous variable $t_{-} y$ ield, and $W$ the exogenous variables, then $\mu^{2}=\Pi^{\prime} Z Z \Pi / \sigma_{v}^{2}$.
} 
Table 8 Test for structural breaks in instrumental variable (chf_eur)

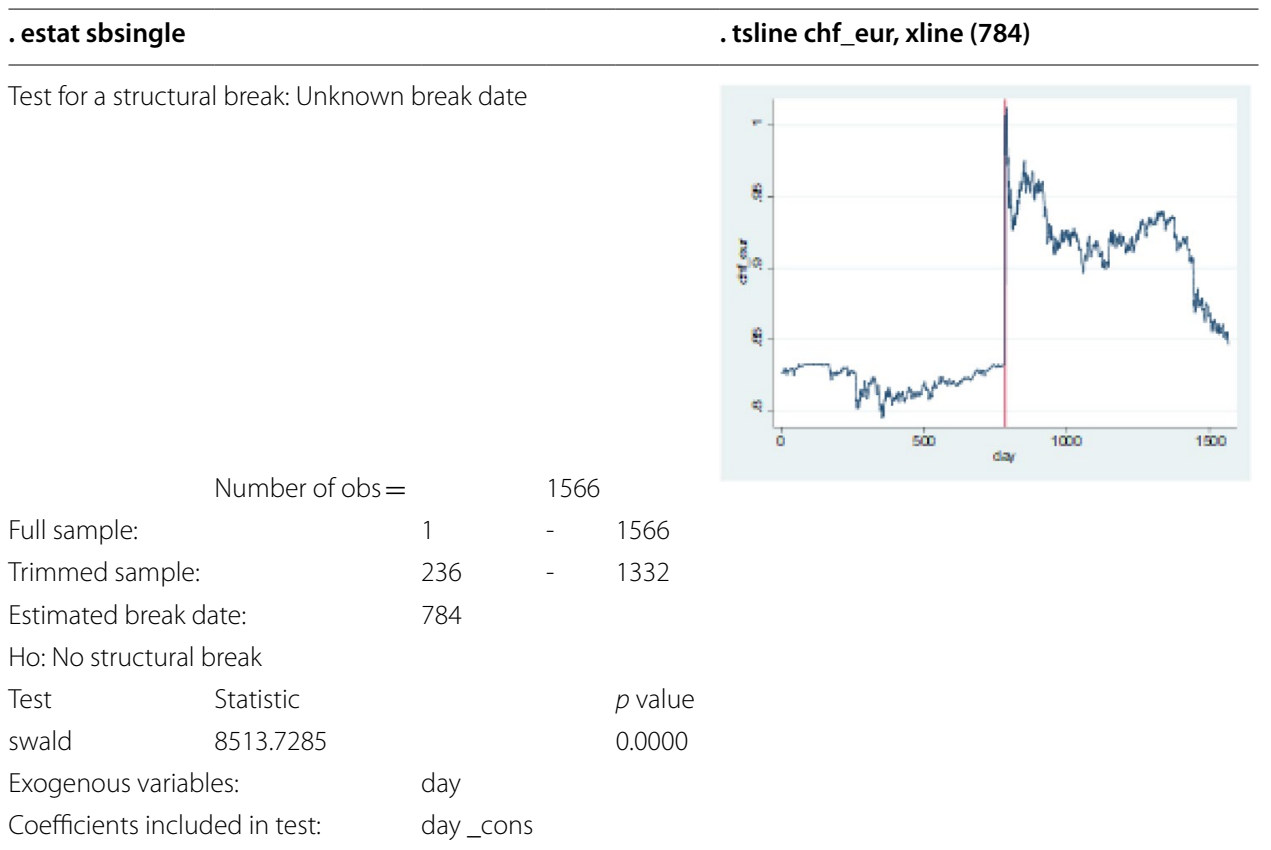

This table indicates that we reject the null hypothesis of no structural break at the $5 \%$ level with a high Wald statistic. The estimated break date in the currency price is the 784 observation from the starting 16jan2012. Source: Own calculations

\section{Discussions and implications}

The results of this research have important policy implications. First, unexpected large currency price shocks may have long-run implications on the municipal bond spreads in Switzerland. The spread has widened after the currency shock of 2015. This is not surprising in the short run, but the new range has become a norm among investors in the long run. This means that some municipalities may still not have benefited as much from the large reduction in the yield levels after the currency shock as they could have before the currency shock.

Second, the default premium of these municipal bonds seems to have been affected the most by the currency shock of 2015. In line with the findings of Schwert (2017) for the US market, in the Swiss market, the default premium also accounts for the largest portion of municipal bond risk premiums. However, in contrast to the US, where a large variety of ratings exist, in the Swiss market, these ratings are limited to just a few. In accordance with this, the default premium is the most sensitive in the Swiss market, explaining the larger change in this premium after relevant shocks in key variables of the economy, including its currency prices. This finding may call for the Swiss authorities to evaluate the effects of default premiumson the cost of financing for those municipalities that hold lower than the highest credit ratings in the market. Furthermore, 18 out of the 26 bonds included in this research hold the highest credit rating, and only two issuers compose those 18 issues from the set of 7 municipalities.

Third, the maturity premium seems to be a very small component in the premium set, and municipalities' debt cost may not be affected much by the term to maturity of the new issues after a currency shock, even though it varied more than the default premium. Thus, municipalities in Switzerland may not save much in their debt costs 
by issuing shorter-term bonds in the long portion of the yield curve. That is, the decision of issuing a 10-year versus an 11-year bond would not affect the price fixings of the municipal bonds in Switzerland. Investors would still set their expected returns based on the 10-year benchmark, regardless. Similar findings are in studies of Shoven and Sialm (2004), Ang et al. (2010), and Ang et al. (2010), where possible municipal bonds are attractive to high-net-worth individuals or in the case of high- and medium-income individuals (Shoven and Sialm 2004). Meanwhile, our results differ from the studies of Wang et al. (2008) and Vukovic et al. (2020a, b, 2021a, b) where maturities premiums are an important component in the municipal bonds premium set.

Further, this research does not offer a conclusive result about the liquidity premium. That is, there is no sufficient evidence to determine whether currency shocks may change the magnitude of this premium in Switzerland at all, even though some correlation between the currency and the liquidity of the bonds was identified in Table 2 . Many reasons may exist behind these results, such as trading platforms where these bonds trade; transaction costs; type of investors that purchase them; and trading strategy, among others, that the models used in this study are not able to capture. It may also be that the tax exemption feature of these bonds is the source of this premium as mentioned by Trzcinka (1982) and Ang, et al. (2010), in which case it would be a matter for further future research in the Swiss market. According to our results, our study is in line with the conclusion of Novy-Marx and Rauh (2011), and Longstaff (2011), that credit/liquidity spread is very small compared to other rates (e.g., the marginal tax rate), or with the finding Wang et al. (2008) that liquidity plays a secondary role to default risk in municipal bond pricing. However, we did not find in our sample results that liquidity takes the highest percent of the average municipal bond spread, as in the study of Ang et al. (2010). Moreover, our study differs most from the research of Jiang (2019) with regards to the results concerning Chinese municipal bonds, where the liquidity risk of municipal bonds is recognized as a key factor that influences the yield spread, with high marginal effects.

In short, the first two implications signal that any attempts to improve the capital costs for the Swiss municipalities may be affected by the foreign exchange policy to some extent, via its impact on the spread, specifically via the impact on the default premium. Whereas the third implication identifies the smallest of all the premiums, although most are affected by the foreign exchange policy.

\section{Conclusions}

This study uses the dis-intervention in the Swiss franc rates in 2015 as a quasi-natural experiment, to explore whether a "no government intervention in the foreign exchange markets" policy could have an impact on the spread of municipal bonds, and change the default, liquidity, and/or maturity premiums, in Switzerland. The empirical study uses the trading data of municipal bonds for the period between January 15, 2015, and January 15, 2018. Two types of two-stage least squares approaches are used to test the impact of the currency shock on the risk premium set. 
The empirical results display that the municipal bond spread has widened an average minimum of $14 \mathrm{bp}$ for the 3-year period after the currency shock of 2015. This spread widens even more as the treasury yields further dive into negative figures. Moreover, the results of the instrumental variables model tests confirm the relevancy of the currency policy on the yield levels of the Swiss economy. The results also display that the marginal impact of the default risk on the yield spread was about -9.298 bp per rating scale before the currency shock of 2015 , and changed to -11.488 well after that currency shock, for the $23.56 \%$ variation of a premium that accounts for $28.07 \%$ of the wider average after the treatment spread.

Based on the above conclusions, this study may suggest that economic policymakers in Switzerland should consider some of the long-run side effects from distortions in their foreign exchange prices. As covered in this research, some of these side effects include the change in the risk premiums of municipal bonds. Moreover, the results may state that to further permit the municipalities to benefit from the lowering of the yield rates in Switzerland, the authorities should focus on improving the default risk of many municipalities, as only two municipalities in Switzerland hold the AA + rating, while the others hold a lower rating. This would allow them to enjoy an additional 11.488 bps average spread reduction. Otherwise, this difference would benefit the investors, while putting a majority of Switzerland's municipalities that do not hold the highest rating at a disadvantage.

This research contributes to the understanding of municipal bond pricing by showing that default risk accounts for a large portion of the municipal bond spread, while maturity risk plays a lesser role. Due to the low frequency of default in this market, it is unusual that default risk is such a driver of yield spreads in Switzerland. This study was not able to identify the role of liquidity as a key driver of municipal bond yields in Switzerland. Further analysis of the tax exemptions environment of the Swiss municipal bonds may be of great help to better understand the pricing of these assets.

Acknowledgements

The authors are grateful to anonymous reviewers for helpful comments that have improved the quality of their work.

Authors' contributions

All authors had equal participation in the writing of all sections of this paper. All authors read and approved the final manuscript.

Funding

No funding was received.

Availability of data and materials

The data that support the findings of this study are available from the corresponding author upon reasonable request.

\section{Declarations}

Competing interests

The authors declare that they have no competing interests.

Received: 17 July 2020 Accepted: 7 August 2021

Published online: 16 August 2021

\footnotetext{
References

Ang A, Longstaff FA (2013) Systemic sovereign credit risk: Lessons from the U.S. and Europe. J Monet Econ 60:493-510

Ang A, Bhansali V, Xing Y (2010) Taxes on tax-exempt bonds. J Financ 65:565-601
} 
Babina T, Jotikasthira C, Lundblad C, Ramadorai T (2015) Heterogeneous taxes and limited risk sharing: evidence from municipal bonds. Working paper, University of North Carolina

Bai J, Perron P (1998) Estimating and testing linear models with multiple structural changes. Econometrica 66:47-78

Bai J, Perron P (2006) Multiple structural change models: a simulation analysis. Econ Theory Pract Front Anal Appl Res $1: 212-237$

Balli F (2009) Spillover effects on government bond yields in euro zone. Does full financial integration exist in European government bond markets? J Econ Finance 33:331. https://doi.org/10.1007/s12197-008-9029-3

Bleaney M, Veleanu V (2021) Redenomination risk in eurozone corporate bond spreads. Eur J Finance. https://doi.org/ $10.1080 / 1351847 X .2021 .1882524$

Breusch TS, Pagan AR (1980) The Lagrange multiplier test and its applications to model specification in econometrics. Rev Econ Stud 47(1):239-253

Dammon RM, Spatt CS, Zhang HH (2004) Optimal asset location and allocation with taxable and tax-deferred investing. J Finance 59:999-1037

Downing C, Zhang F (2004) Trading activity and price volatility in the municipal bond market. J Finance 59:899-931

Eikon Refinitiv platform (2020) https://solutions.refinitiv.com/eikon-trading-software?utm_content=Refinitiv\%20Bra nd\%20Product-CEE-EMEA-G-EN-BMM\&utm_medium\%20=cpc\&utm_source=google\&utm_campaign=68832 RefinitivBAUPaidSearch\&elqCampaignld=5917\&utm_term=\%20\%20refinitiv\%20\%20eikon\&gclid=EAlalQobCh MI5eiJ_OjO6glVgbHtCh3ODAUaEAAYASAAEgKcvPD_BwE

Fabozzi F (2007) Fixed income analysis, 2nd edn. Wiley, Hoboken

Fabozzi F (2009) Bond markets, analysis and strategies, 7th edn. Prentice Hall, Upper Saddle River

Fama EF (1977) A pricing model for the municipal bond market. Working paper, University of Chicago

Galper H, Peterson J (1971) An analysis of subsidy plans to support state and local borrowing. Natl Tax J 24:344-367

Green RC (1993) A simple model of the taxable and tax-exempt yield curves. Rev Financ Stud 6:233-264

Green RC (2007) Issuers, underwriter syndicates, and aftermarket transparency. J Finance 62:1529-1550

Green RC, Odegaard BA (1997) Are there tax effects in the relative pricing of U.S. government bonds. J Finance 52:609-633

Green R, Li D, Schurhoff N (2010) Price discovery in illiquid markets: do financial asset prices rise faster than they fall? J Finance 65:1669-1702

Grubisic Z, Zaric S, Vukovic D (2011) FDI inflow in see countries and its consequences in the context of the financial crisis. Finance and the performance of firms in science, education, and practice. Tomas Bata University in Zlin, Czech Republic. (edt.) Drahomira Pavelkova (proceedings paper), pp 116-129

Gujarati DN, Porter DC, Gunasekar S (2012) Basic econometrics. McGraw-Hill, New York

Harris M (1990) Liquidity, trading rules, and electronic trading system. Monogragh Series of Finance and Economics. NYU Salomon Center

Hempel G (1972) An evaluation of municipal bankruptcy laws and proceedings. J Finance 27:1012-1029

Jiang XW (2019) The impact of government intervention on municipal bond liquidity premium: evidence from China. Appl Econ Finance 6(3):79-86

Kimbal R (1977) Commercial banks, tax-avoidance and the market for state and local debt. N Engl Econ Rev January/ February:80-97

Knezevic D, Nordström M, Österholm P (2021) The relation between municipal and government bond yields in an era of unconventional monetary policy. Econ Notes 50:e12176

Kou G, Xu Y, Peng Y, Shen F, Chen Y, Chang K, Kou S (2021a) Bankruptcy prediction for SMEs using transactional data and two-stage multiobjective feature selection. Decis Support Syst 140:113429

Kou G, Akdeniz ÖO, Dinçer H, Yüksel S (2021 b) Fintech investments in European banks: a hybrid IT2 fuzzy multidimensional decision-making approach. Financ Innov 7(1):1-28

Landoni M (2018) Tax distortions and bond issue pricing. J Financ Econ 129:382-393

Li D, Schürhoff N (2019) Dealer networks. J Finance 94:91-144

Lleo S, Ziemba WT (2015) The Swiss black swan bad scenario: is Switzerland another casualty of the Eurozone crisis? Int J Financ Stud 3:351-380

Longstaff $F$ (2011) Municipal debt and marginal tax rates: Is there a tax premium in asset prices? J Finance 66:721-751

Maiti M, Krakovich V, Shams R, Vukovic D (2020) Resource based model for small innovative enterprises. Manag Decis 58(8):1525-1541

Manchester P, Davies A (2009) Implications of foreign investment patterns for federal, state, and local bond financing. Working paper, Duquesne University

Miller M (1977) Debt and Taxes. J Finance 32(2):261-275

Novy-Marx R, Rauh JD (2011) Public pension promises: how big are they and what are they worth? J Finance 66:1211-1249

Schwert M (2017) Municipal bond liquidity and default risk. J Finance 72:1683-1722

Shoven JB, Sialm C (2004) Asset location in tax-deferred and conventional savings accounts. J Public Econ $88(1-2): 23-38$

Swiss National Bank (2015) Swiss National Bank discontinues minimum exchange rate and lowers interest rate to $-0.75 \%$ (2015/01/15). Retrieved from http://www.snb.ch/en/ifor/media/id/media_releases?dsrp_4474c485. page $=4$

The Economist (2015) Why the Swiss unpegged the franc. https://www.economist.com/the-economist-explains/ 2015/01/18/why-the-swiss-unpegged-the-franc. Accessed 10 Nov 2019

Trzcinka C (1982) The pricing of tax-exempt bonds and the miller hypothesis. J Finance 37(4):907-923

Vukovic DB, Prosin V (2018) The prospective low risk hedge fund capital allocation line model: evidence from the debt market. Oeconomia Copernicana 9(3):419-439

Vukovic D, Lapshina K, Maiti M (2019) European monetary union bond market dynamics: pre \& post crisis. Res Int Bus Finance 50:369-380. https://doi.org/10.1016/j.ribaf.2019.04.001 
Vukovic D, Vyklyuk Y, Matsiuk N, Maiti M (2020a) Neural network forecasting in prediction Sharpe ratio: evidence from EU debt market. Phys A Stat Mech Appl 1-20:123331. https://doi.org/10.1016/j.physa.2019.123331

Vukovic D, Maiti M, Kochetkov D, Bystryakov A (2020b) How attractive are municipal bonds for the passive competitiveness: the case of immunization of municipal bonds. Compet Rev. https://doi.org/10.1108/CR-02-2020-0024 Vukovic D, Prosin V, Maiti M (2021a) A study on the factors that governs US and EU YTM. Acc Manag (contaduría y Admin) 66(3):1-28

Vukovic D, Lapshina K, Maiti M (2021 b) Wavelet coherence analysis of returns, volatility and interdependence of the US and the EU money markets: pre \& post crisis. N Am J Econ Finance 58:101457

Wang J, Wu C, Zhang FX (2008) Liquidity, default, taxes and yields on municipal bonds. J Bank Finance 32:1133-1149 Wei B, Yue WZ (2020) Liquidity backstops and dynamic debt runs. J Econ Dyn Control 116:103916. https://doi.org/10. 1016/j.jedc.2020.103916

Wen F, Xu L, Ouyang G, Kou G (2019) Retail investor attention and stock price crash risk: evidence from China. Int Rev Financ Anal 65:101376

Wooldridge JM (2002) Econometric analysis of cross section and panel data. MIT Press

Wooldridge JM (2009) Introductory econometrics: a modern approach, 4th edn. South-Western College Publ, New York

Wu C, Yoo W (2016) Liquidity, taxes and yield spreads between tax-exempt and taxable bonds . J Finance 37:1141-1150

Zha Q, Kou G, Zhang H, Liang H, Chen X, Li CC, Dong Y (2020) Opinion dynamics in finance and business: a literature review and research opportunities. Financ Innov 6(1):1-22

Zimmerman J (1977) The municipal accounting maze: an analysis of political incentives. J Acc Res supplement:107-144

\section{Publisher's Note}

Springer Nature remains neutral with regard to jurisdictional claims in published maps and institutional affiliations.

\section{Submit your manuscript to a SpringerOpen ${ }^{\odot}$ journal and benefit from:}

- Convenient online submission

Rigorous peer review

- Open access: articles freely available online

- High visibility within the field

- Retaining the copyright to your article

Submit your next manuscript at $\mathbf{s p r i n g e r o p e n . c o m ~}$ 